University of Wollongong

Research Online

Australian Institute for Innovative Materials -

Papers

Australian Institute for Innovative Materials

$1-1-2018$

\title{
Metal-organic framework-derived one-dimensional porous or hollow carbon-based nanofibers for energy storage and conversion
}

Chaohai Wang

Nanjing University of Science and Technology

Yusuf Valentino Kaneti

Qingdao University of Science and Technology, National Institute for Materials Science

Yoshio Bando

University of Wollongong, National Institute for Materials Science, yoshio@uow.edu.au

Jianjian Lin

Qingdao University of Science and Technology, jl824@uowmail.edu.au

Chao Liu

Nanjing University of Science and Technology

See next page for additional authors

Follow this and additional works at: https://ro.uow.edu.au/aiimpapers

Part of the Engineering Commons, and the Physical Sciences and Mathematics Commons

Research Online is the open access institutional repository for the University of Wollongong. For further information contact the UOW Library: research-pubs@uow.edu.au 


\title{
Metal-organic framework-derived one-dimensional porous or hollow carbon- based nanofibers for energy storage and conversion
}

\author{
Abstract \\ Metal organic framework (MOF)-derived nanoporous carbons (NPCs) have been proposed as promising \\ electrode materials for energy storage and conversion devices. However, MOF-derived NPCs typically \\ suffer from poor electrical conductivity due to the lack of connectivity between these particles and a \\ micropore-dominated storage mechanism, which hinder mass and electron transfer, thereby leading to \\ poor electrochemical performance. In recent years, one-dimensional (1D) MOF-derived carbon \\ nanostructures obtained using an electrospinning method have emerged as promising materials for both \\ electrochemical energy storage (EES) and energy conversion applications. In this mini review, the recent \\ progress in the development of MOF-derived 1D porous or hollow carbon nanofibers using the \\ electrospinning method and their application in energy storage (e.g., supercapacitors and rechargeable \\ batteries) and conversion devices (e.g., fuel cells) is presented. The synthetic method, formation \\ mechanism and the structure-activity relationship of such porous or hollow carbon nanofibers are also \\ discussed in detail. Finally, future perspectives on the development of electrospun MOF-derived carbon \\ nanomaterials for energy storage and conversion applications are provided. This review will provide some \\ guidance for future derivations of 1D hollow carbon nanomaterials from MOFs using electrospinning \\ technology. \\ Disciplines \\ Engineering | Physical Sciences and Mathematics

\section{Publication Details} \\ Wang, C., Kaneti, Y. Valentino., Bando, Y., Lin, J., Liu, C., Li, J. \& Yamauchi, Y. (2018). Metal-organic \\ framework-derived one-dimensional porous or hollow carbon-based nanofibers for energy storage and \\ conversion. Materials Horizons, 5 (3), 394-407.
}

\section{Authors}

Chaohai Wang, Yusuf Valentino Kaneti, Yoshio Bando, Jianjian Lin, Chao Liu, Jiansheng Li, and Yusuke Yamauchi 
1 Metal-Organic Framework-Derived One-Dimensional Porous or Hollow Carbon-Based

1 Jiangsu Key Laboratory of Chemical Pollution Control and Resources Reuse, School of Environmental 
Metal organic framework (MOF)-derived nanoporous carbons (NPCs) have been proposed as promising 3 electrode materials for energy storage and conversion devices. However, MOF-derived NPCs typically suffer 4 from poor electrical conductivity due to the lack of connectivity between these particles and micropore5 dominated storage mechanism, which hinder mass and electron transfer, thereby leading to poor electrochemical 6 performance. In recent years, one-dimensional (1D) MOF-derived carbon nanostructures obtained using 7 electrospinning method have emerged as promising materials for both electrochemical energy storage (EES) 8 and energy conversion applications. In this mini review, the recent progress in the development of MOF-derived 9 1D porous or hollow carbon nanofibers using electrospinning method and their applications for energy storage 10 (e.g., supercapacitors and rechargeable batteries) and conversion (e.g., fuel cells) is presented. The synthetic 11 method, formation mechanism and the structure-activity relationship of such porous or hollow carbon 12 nanofibers are also discussed in detail. Finally, the future perspectives on the development of electrospun MOF13 derived carbon nanomaterials for energy storage and conversion applications are provided. This review will 14 provide some guidance for future derivations of 1D hollow carbon nanomaterials from MOFs using electrospinning technology.

17 Keywords: Metal-organic frameworks; hollow carbon nanofibers; nanoporous carbons; energy storage and conversion; electrospinning 


\section{Introduction}

The rapid increase in world economy has led to a significant increase in global energy requirement, leading to rising concerns of energy shortage and climate change problems for the society. ${ }^{1-5}$ As a result, the development of highly efficient, renewable and clean energy sources is becoming increasingly important. In recent years, many efforts have been devoted to develop various rechargeable and reversible energy storage and conversion devices, such as supercapacitors, ${ }^{6-8}$ fuel cells, ${ }^{9-12}$ solar cells, ${ }^{13-15}$ and lithium-ion batteries (LIBs). ${ }^{16-18}$ The results demonstrate that the achievement of EES devices with high energy and power densities require the design and construction of high-performance electrode materials combined with the suitable use of electrolytes. ${ }^{19,20}$

Metal-organic frameworks (MOFs), an emerging but rapidly growing class of porous materials, are assembled by connecting metal ions or clusters with organic linkers. They have attracted considerable interest since firstly reported in 1995. ${ }^{21-23}$ Compared with traditional porous materials, the main advantage of MOFs is their controllable structure and tunable porosity at the molecular level by tuning metal species and organic links. As a result of these advantages, MOFs have been widely applied in adsorption, ${ }^{24,}{ }^{25}$ gas storage/separation, ${ }^{26-29}$ catalysis, ${ }^{30-32}$ and drug delivery. ${ }^{33-35}$ In recent years, the exploration of MOFs in energy storage and conversion applications, such as supercapacitors, ${ }^{36}$ fuel cells, ${ }^{9}$ and lithium-ion batteries ${ }^{37,} 38$ has gained significant attention. However, the poor electrical conductivity and low stability of pure MOFs have impeded their full potential for these applications. More recently, MOFs have received significant attention as novel templates to derive nanoporous carbons (NPCs) for energy storage and conversion applications. ${ }^{39-42}$ Since the first report of such derivation by Xu et al. ${ }^{43}$ in 2008 and a subsequent report by Yamauchi et al. ${ }^{44}$ in 2012, significant advances have been made in the derivation of NPCs from MOFs and the related publications are continuously growing every year (Fig. 1). ${ }^{45-49}$ The development process in the composition and morphology of MOF-derived NPCs is

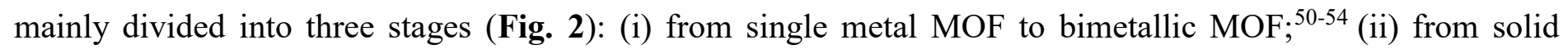
structure to hollow structure; the strategies for preparing hollow structures include etching, ${ }^{55}$ rigid inducing/confined pyrolysis, ${ }^{56}$ and templated method $;{ }^{57}$ and (iii) from zero dimension (0D) polyhedral to 1D rods, ${ }^{58-60} 2 \mathrm{D}$ sheets, ${ }^{61-63}$ and 3D arrays. ${ }^{64-66}$ Compared with 0D, 2D, and 3D nanomaterials, 1D nanostructures, especially those with porous or hollow structures possess many advantages for energy storage and conversion devices. First, porous or hollow structures offer more active sites and reduce the path of transport for both mass and charge. Second, 1D nanomaterials can provide fast pathways for electron transport, and lastly, they can be easily grown on thin films to form self-standing flexible energy storage devices. ${ }^{67-71}$ Due to these advantages, more efforts have been dedicated in recent years to fabricate porous or hollow 1D carbon nanomaterials from MOFs.

Electrospinning, as a versatile and scalable method, has attracted significant interest in both scientific 
1 research and practical applications. ${ }^{72}$ Together with carbonization, this method provides a facile and convenient

2 way for preparing 1D porous (PCNFs) or hollow carbon nanofibers (HCNFs). ${ }^{4,}$ 19, 73-78 Our group has previously

3 reported the fabrication of electrospun MOF-derived PCNFs and HCNFs for energy storage applications. ${ }^{79}, 80$

4 MOF-derived PCNFs and HCNFs have emerged as a novel kind of carbon materials for energy storage and 5 conversion applications. In this mini review, we will focus on the recent progress in the fabrication of MOF-

6 derived 1D PCNFs and HCNFs by electrospinning for energy storage and conversion applications (e.g., 7 supercapacitors, rechargeable batteries, and fuel cells). Herein, we will cover the use of electrospinning method 8 for synthesizing MOF-derived PCNFs and HCNFs and discuss their formation mechanisms, along with their 9 important application in these devices. Finally, the future perspectives of electrospun MOF-derived PCNFs and 10 HCNFs for energy storage and conversion applications are also presented.

\section{Synthesis and formation mechanism of MOF-derived HCNFs by electrospinning}

Electrospinning provides a simple and low-cost method for preparing 1D nanomaterials and it is by far the most commonly used method for fabricating MOF-derived 1D PCNFs or HCNFs. ${ }^{80-83}$ Up to now, there are two main approaches for fabricating electrospun MOF-based nanofibers (Fig. 3). In route I, MOF nanoparticles are firstly synthesized and then, they are mixed with the polymer to form a homogeneous solution. Next, this precursor solution can be converted into MOF-based nanofibers by electrospinning. In route II, electrospun polymer nanofibers (containing metal ions) are firstly prepared and then, the MOF nanoparticles are grown insitu on the polymer nanofibers. Finally, the 1D PCNFs or HCNFs are obtained by directly carbonizing the MOF nanofibers under inert atmosphere. To explain the formation mechanism of 1D PCNFs from the electrospinning and subsequent carbonization of $\mathrm{MOF} /$ polymer mixtures, zeolitic imidazolate framework-8 (ZIF8)/polyvinylpyrrolidone (PVP) nanofibers are selected as a typical model. ${ }^{84}$ As depicted in Fig. 4, the surface of ZIF-8 polyhedrons possesses abundant $\mathrm{Zn}^{2+}$ sites which can coordinate easily with $\mathrm{C}=\mathrm{O}$ groups present abundantly in PVP. As a result of this coordination effect, the ZIF-8 polyhedrons in the mixture of ZIF-8/PVP are evenly distributed and encapsulated by PVP at a low temperature. Following heat-treatment at $500{ }^{\circ} \mathrm{C}$, the PVP in the mixture decomposed to an amorphous carbon network, while the ZIF-8 polyhedrons retained their crystal structure. Owing to the low calcination temperature, the PVP-derived carbon still possesses numerous $\mathrm{C}=\mathrm{O}$ bonds which can generate a new and strong interface between ZIF-8 and PVP-derived carbon. With the increase in calcination temperature, the ZIF-8 polyhedrons start to decompose. The strong cohesive interface interaction between PVP-derived carbon and ZIF-8 polyhedrons offers a unique confinement effect which maintains the ZIF-8-derived carbon adjacent to the internal surface of PVP-derived carbon.

Another example is the fabrication of 1D HCNFs using the electrospinning and post-synthesis carbonization of a mixture of ZIF-8/PAN nanofibers. ${ }^{79}$ To generate the ZIF-8/PAN nanofibers, ZIF-8 nanoparticles are firstly 
1 coated with a layer of PAN. Due to the capability of $\mathrm{Zn}^{2+}$ to coordinate with $-\mathrm{C} \equiv \mathrm{N}$ groups existing on the

2 surface of PAN nanofibers, the ZIF-8 particles become tightly encapsulated by the PAN nanofibers. At a low 3 calcination temperature $\left(500^{\circ} \mathrm{C}\right)$, the PAN-derived carbon typically still exhibits many $-\mathrm{C} \equiv \mathrm{N}$ groups which can

4 form a new strong interface between the ZIF-8 surface and the PAN-derived carbon shell. This consequently 5 causes the decomposition of the ZIF-8 particles, which is accompanied by their shrinkage starting from inside to 6 outside, thereby leading to the generation of hollow structure. The formation of such hollow structure can be 7 described as a confinement effect or an interface induction effect, which has been observed in other systems, 8 such as, ZIF-8@ $\mathrm{SiO}_{2} .{ }^{56}$ On the other hand, if no other interaction exists between the surface of the ZIF-8 nanoparticles and the PAN layer, inward contraction takes place and a solid structure is achieved. Apart from PAN and PVP, PVA has previously been used to prepare $\mathrm{ZnO}$ quantum dot (QD)-decorated carbon nanofibers. ${ }^{85}$ This was possible due to the oxygen rich nature of PVA, which enabled it to react with the ZIF-8 particles during carbonization of the ZIF-8/PVA nanofibers to generate ZnO QDs@carbons on the CNF surface.

\section{MOF-derived HCNF materials for energy storage and conversion applications}

\subsection{Supercapacitors}

Supercapacitors (SCs) are considered as promising energy storage devices owing to their unique features, such as high power density, fast charging rate, and long cycling life. ${ }^{8,49}$ The most significant parameters which govern the capacitive performance of SC electrodes are pore size distribution, conductivity, and surface area. ${ }^{8,86}$ MOF-derived NPCs with high surface areas and tunable pore size have been widely investigated as potential electrode materials in SCs applications in the past decade. ${ }^{47}, 87-89$ However, the low conductivity of MOFderived NPCs typically leads to lower specific capacitance, which is often attributed to the poor interconnectivity between these particles. Generally, the specific capacitance of MOF-derived NPCs is around $100-300 \mathrm{~F} \mathrm{~g}^{-1}$ in aqueous electrolytes, which is only slightly higher than activated carbons. ${ }^{88}$

Recently, electrospinning method combined with carbonization has been proposed as an attractive route to increase the electrical conductivity of MOF-derived NPCs. Previously, our group has fabricated 1D nanoporous carbon fibers (NPCFs) via electrospinning for SC. In our proposed method, ZIF-8 nanoparticles were mixed with PAN solution and converted into ZIF-8/PAN fibers by electrospinning, before being heat-treated at $500{ }^{\circ} \mathrm{C}$ under inert atmosphere to obtain NPCFs. ${ }^{79}$ As evident in Fig. 5a, the ZIF-8 nanoparticles were transformed into hollow structures after the carbonization process. The CV curves of the NPCFs at various scan rates (Fig. 5b) revealed their electric double-layer capacitance and the galvanostatic charge-discharge measurements at various applied currents indicated their favourable conductive behaviors (Fig. 5c). The specific capacitances of PANderived carbon (PAN-C), ZIF-8-derived NPC (ZIF-8-NPC), and NPCF were measured to be 110, 201, and 332 $\mathrm{F} \mathrm{g} \mathrm{g}^{-1}$, respectively, at $1 \mathrm{~A} \mathrm{~g}^{-1}$ (Fig. 5d). The enhanced specific capacitance of NPCFs was contributed by their 
1 enhanced electrical conductivity, which resulted from the improved interconnectivity between the ZIF-8-derived NPCs. Such improved interconnectivity was possible due to the linking of these particles by the chains of PANderived carbon, which provided a pathway to enable smooth charge transport and ionic diffusion during charge/discharge. The Nyquist plots confirmed the higher electrical conductivity of NPCFs compared to PAN-C and ZIF-8-NPC, which was further supported by the four-probe method measurements (Fig. 5e).

Apart from PAN, 1D conductive polyaniline (PANI) nanofibers have also attracted considerable attention as electrode materials for SCs, owing to their simple and low-cost fabrication, high chemical stability, and good electrical conductivity. ${ }^{90}$ Previously, 3D cross-linked PANI/N-doped porous carbon fibers (3D-CPC) have been obtained from the in-situ polymerization of ZIF-8-derived N-doped porous carbon fibers with aniline. ${ }^{91}$ The galvanostatic charge-discharge measurements revealed the higher specific capacitance of the $3 \mathrm{D}-\mathrm{CPC}\left(75 \mathrm{~F} \mathrm{~g} \mathrm{~g}^{-1}\right)$ relative to 3D cross-linked PANI $\left(504 \mathrm{~F} \mathrm{~g}^{-1}\right)$ and $\mathrm{N}$-doped porous carbon $\left(325 \mathrm{~F} \mathrm{~g}^{-1}\right)$ at a current density of $1 \mathrm{~A}$ $\mathrm{g}^{-1}$. Furthermore, the specific capacitance of the 3D-CPC only slightly decreased from 755 to $618 \mathrm{~F} \mathrm{~g}^{-1}$, with the increase in current density from 1 to $20 \mathrm{~A} \mathrm{~g}^{-1}$, indicating its superior rate performance. In addition, the 3D-CPC electrode also showed good cycling performance with high capacitance retention of $91.2 \%$ after 1000 cycles at a high current density of $20 \mathrm{~A} \mathrm{~g}^{-1}$. The excellent electrochemical properties of the 3D-CPC for SC were ascribed to the $\mathrm{N}$-doped porous carbon which could offer more active sites for the fast transfer of ions and electrons and the high structural stability of the 3D cross-linked PANI fiber which could prevent the electrode material from swelling and shrinking.

The electrochemical performance of MOF-derived CNFs for SCs can be further enhanced by combining them with pseudocapacitive materials. ${ }^{85,92}$ For instance, hierarchical nanofibers composed of numerous $\mathrm{ZnO}$ QDs@carbons and CNFs prepared via the carbonization of electrospun ZIF-8/poly(vinyl alcohol) (PVA) nanofibers displayed improved specific capacitance $\left(346 \mathrm{~F} \mathrm{~g}^{-1}\right.$ at $\left.0.5 \mathrm{~A} \mathrm{~g}^{-1}\right)$ and enhanced rate capability $(79 \%$ capacitance retention at $8 \mathrm{~A} \mathrm{~g} \mathrm{~g}^{-1}$ ) compared to ZIF-8-derived carbon and pure CNFs. ${ }^{85}$ The outstanding electrochemical performance of the ZnO QDs-decorated CNFs (ZPCNFs) was attributed to several reasons. First, the uniformly dispersed ZnO QDs throughout the entire CNFs would increase the total capacitance of the composite by offering pseudocapacitance. Second, the 1D CNFs could provide highly conductive pathways for the transport of electrons during the charge/discharge process. Lastly, the hierarchical pores of the ZPCNFs offered many electroactive sites and electrolyte transfer channels to enhance the transportation of ions throughout the architecture, leading to improved capacitance and rate capability.

An integrated self-charging power system combining flexible fiber-shaped coaxial asymmetric supercapacitors (FASCs) with flexible triboelectric nanogenerators (FTENGs) can enable simultaneous harvesting and storage of energy for providing power for flexible electronics. ${ }^{93}$ Uniform carbon nanotubes fibers (CNTFs)@ZnCo $\mathrm{O}_{4} @ \mathrm{Zn}-\mathrm{Co}-\mathrm{S}$ hybrid array (HA) derived from bimetallic Zn-Co-ZIF have previously 
1 been utilized to fabricate such self-charged power system. ${ }^{94}$ To obtain the hybrid array, the CNTFs were initially 2 immersed in a mixture solution containing $\mathrm{Zn}^{2+}$ and $\mathrm{Co}^{2+}$ solution under hydrothermal conditions and the 3 resulting product was heat-treated at $350{ }^{\circ} \mathrm{C}$ under inert atmosphere to obtain the $\mathrm{CNTFs@} \mathrm{ZnCo}_{2} \mathrm{O}_{4}$ nanowire 4 array (NA). The grown $\mathrm{ZnCo}_{2} \mathrm{O}_{4} \mathrm{NA}$ was subsequently used as a source of both $\mathrm{Zn}^{2+}$ and $\mathrm{Co}^{2+}$ ions as well as a 5 skeleton for the in-situ growth of the bimetallic Zn/Co-ZIF (CNTFs@ZnCo $\left.\mathrm{C}_{4} @ \mathrm{Zn} / \mathrm{Co}-\mathrm{ZIF}\right)$. The final

conversion to CNTFs@ZnCo $2 \mathrm{O}_{4} @ \mathrm{Zn}-\mathrm{Co}-\mathrm{S} H A$ was achieved by heat-treating the CNTFs@ZnCo $2 \mathrm{O}_{4} @ \mathrm{Zn}_{2} \mathrm{Co}_{-}$ ZIF HA in air at $350{ }^{\circ} \mathrm{C}$ to convert it to CNTFs@ $\mathrm{ZnCo}_{2} \mathrm{O}_{4} @ \mathrm{ZnCo}_{2} \mathrm{O}_{4} \mathrm{HA}$, followed by a secondary reaction with thioacetamide at $70{ }^{\circ} \mathrm{C}$. The flexible FASC device was assembled by utilizing the CNTFs@ZnCo $2 \mathrm{O}_{4} @ \mathrm{Zn}_{-}$ Co-S as the cathode and the CNTFs@H-Co $\mathrm{O}_{4} @ \mathrm{CoNC} \mathrm{HA}$ as the anode. This FASC device showed a high specific capacitance of $117.18 \mathrm{mF} \mathrm{cm}^{-2}$ at a current density of $1 \mathrm{~mA} \mathrm{~cm}{ }^{-2}$, which slightly decreased to $67.5 \mathrm{mF}$ $\mathrm{cm}^{-2}$ with the increase of current density to $10 \mathrm{~mA} \mathrm{~cm}$. The excellent electrochemical performance of this FASC device was further highlighted by its high areal energy density of $32.01 \mu \mathrm{W} \mathrm{h} \mathrm{cm}{ }^{-2}$ at an areal power density of $698.42 \mu \mathrm{W} \mathrm{cm} \mathrm{cm}^{-2}$. Moreover, when the power density was increased to $7000 \mu \mathrm{W} \mathrm{cm}^{-2}$, the energy density of the device still remained as high as $12.38 \mu \mathrm{W} \mathrm{h} \mathrm{cm}$, suggesting the synergistic effect of the CNTFs@ZnCo $2 \mathrm{O}_{4} @ Z$ Zn-Co-S HA. The excellent electrochemical performance of the assembled FASC device was attributed to the unique hierarchical and porous structure which provided many electroactive sites and a facile ion diffusion path.

From the above reports, it is evident that electrospinning is a feasible and attractive method for preparing 1D MOF-derived PCNFs or HCNFs with high electrochemical performance for SC applications. In general, the benefits of MOF-derived PCNFs or HCNFs for SC applications are:

- High structural stability which prevents significant swelling and shrinkage of the electrode.

- Hierarchical porosity which provides many electroactive sites for ions and numerous electrolyte transfer channels to enhance ionic transport throughout the structure.

- $1 D$ fiber-like structure which offers highly conductive pathways for the transport of electrons during charge/discharge.

- Improved interconnection between the MOF-derived NPCs which provided a 'pathway' to enable efficient charge transport and ionic diffusion during charge/discharge.

Despite the significant progress in this field, many previous reports tend to focus on ZIF-derived carbons and more studies are needed on the preparation of 1D PCNFs or HCNFs from other MOFs in the future.

\subsection{Rechargeable batteries}

Rechargeable batteries, such as LIBs and sodium-ion batteries (SIBs) are among the most popular energy storage systems in our daily lives, playing important roles in personal computers, smart grids, and electrical 
1 vehicles. ${ }^{95-97}$ One of the key factors which determine the performance of rechargeable batteries is the electrode materials. Therefore, many studies have been carried out to develop advanced electrode materials with high specific capacity, good rate performance, and excellent cycling stability. Electrospun MOF-derived PCNFs or HCNFs possess high surface area, good electrical conductivity, and hierarchically porous structures, which make them promising electrode materials for rechargeable batteries. For instance, Lou et al. have demonstrated the excellent electrochemical properties of hierarchical $\mathrm{Co}_{3} \mathrm{O}_{4} / \mathrm{CNT}$ microtubes derived from the in-situ growth of ZIF-67 on electrospun polyacrylonitrile (PAN) nanofibers for LIBs (Fig. 6a) ${ }^{98}$ The hollow nature of the ZIF67/PAN-derived $\mathrm{Co}_{3} \mathrm{O}_{4} / \mathrm{CNT}$ microtubes can be clearly observed in Fig 6b-d, which was attributed to the Kirkendall effect during the annealing process. Due to their hierarchical hollow architectures, the volume variations which occurred during charge-discharge processes could be effectively minimized. As a result, the ZIF-67/PAN-derived $\mathrm{Co}_{3} \mathrm{O}_{4} / \mathrm{CNT}$ microtubes exhibited good rate performance, with the reversible capacity being decreased only slightly from $832 \mathrm{mAh} \mathrm{g}^{-1}$ at $0.75 \mathrm{~A} \mathrm{~g}^{-1}$ to $643 \mathrm{mAh} \mathrm{g}^{-1}$ at $3 \mathrm{~A} \mathrm{~g}^{-1}$ (Fig. 6e) and good cycling stability with no obvious capacity fading after 200 cycles at $1 \mathrm{~A} \mathrm{~g}^{-1}$ (Fig. 6f). Goodenough and coworkers reported the fabrication of nitrogen-doped hollow porous carbon nanofibers (HPCNFs-N) through the in-situ growth of bimetallic ZIF (Zn-Co-ZIF, BMZIF) on PAN nanofibers for SIBs (Fig. 6g). ${ }^{99}$ The BMZIF can combine the advantages of each individual ZIF material (ZIF-8 affords the porous structure and nitrogen doping; ZIF-67 provides highly graphitized carbon). As a result, the synthesized N-doped CNFs showed excellent electrochemical performance with high reversible capacities of up to $346 \mathrm{mAh} \mathrm{g}^{-1}$ and excellent cycling life of over 10,000 cycles with no visible decrease in capacity when employed as an anode material for SIBs (Fig. 6h).

Lithium-sulfur (Li-S) batteries have gained increasing attention in recent years due to their lightweight nature and high energy density. Theoretically, Li-S batteries can deliver a large specific capacity as high as

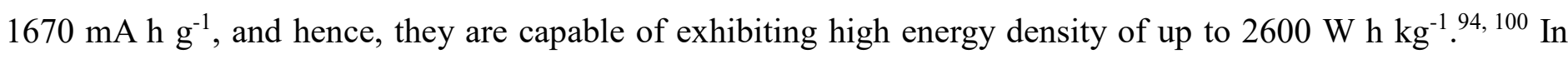
addition, Li-sulfur batteries show other advantages compared to LIBs, such as lower fabrication cost, environmental friendliness, and wide availability of the electrode-active sulfur material. However, there exist some challenges which need to be solved before they can be commercialized for use in electronic devices and hybrid vehicles. These challenges include low electrode utilization, poor high-rate performance, and rapid fade in capacity, due to the poor ionic or electronic conductivity of sulfur and dissolution of the intermediate polysulfides in the electrolyte, also known as the 'shuttle effect'. Porous carbon materials, e.g., microporous, mesoporous, and macroporous carbon, have been widely investigated as cathode hosts for Li-S batteries. In general, macroporous carbon is not so effective in activating enclosed sulfur and restricting soluble polysulfides, which causes poor long-term stability. In comparison, mesoporous carbon materials have been successfully used to some extent to prepare sulfur cathodes with better long-term cycling stability, however, the 
1 electrochemistry of cyclo- $\mathrm{S}_{8}$ still remains in the systems, and the dissolution and shuttle effect of polysulfides remain a major problem. ${ }^{101}$ In recent years, microporous carbon materials have been proposed as an ideal cathode host for sulfur. ${ }^{102,103}$ For instance, the loading of sulfur into microporous carbon fibers with an average pore size of around $1 \mathrm{~nm}$, the catalytic activity and cycling stability of sulfur could be significantly enhanced. ${ }^{102}$

Nonetheless, it is still difficult to completely solve the problems arising from the electrochemistry of cyclo-S . As such, it is desirable to load sulfur into carbon substrates with hierarchical porosity to enable optimized confinement of sulfur. In such hierarchical porous carbon materials, the micropores will enable the storage of sulfur as chain-like sulfur molecules to ensure high specific capacity and good cycling performance, whereas the presence of mesopores will increase the pore volume of the carbon materials to achieve a high amount of sulfur loading and ensure the smooth transfer of Li ions to promote high rate capability. ${ }^{101}$

MOF-derived microporous carbon polyhedrons (MCPs) encapsulated PAN nanofibers have previously been proposed as effective sulfur immobilizer for Li-S batteries, owing to the possibility to disperse sulfur uniformly inside the nanofibers and in the micropores of MCPs. ${ }^{94}$ The encapsulation process was achieved by electrospinning a mixture of MCPs and PAN, followed by the loading of sulfur via a two-step reaction at $155^{\circ} \mathrm{C}$ and at $300{ }^{\circ} \mathrm{C}$, respectively. The optimized S/MCPs-PAN composite (containing 52 wt \% sulfur) exhibited an initial large reversible capacity of around $790 \mathrm{mAh} \mathrm{g}^{-1}$, which only slightly decreased to $789.7 \mathrm{mAh} \mathrm{g}^{-1}$ in the second cycle, and the discharge capacity was maintained at $666.2 \mathrm{mAh} \mathrm{g}^{-1}$ after 200 cycles, indicating both high sulfur utilization (90.7\%), and good capacity retention (84.4\%). The good electrochemical performance of the S/MCPs-PAN-52 composite was attributed to its high structural stability which offers 3D ionic or electronic transport paths and its effective sulfur utilization owing to the existence of micropores. However, when the sulfur content was increased to $65 \%$, the resulting composite showed low utilization of sulfur and poor rate performance due to the formation of a thick solid electrolyte interphase (SEI) layer. These results indicate that the state and content of sulfur can influence the utilization and reversible capacity of sulfur cathode in carbonate-based electrolytes greatly. Specifically, when a low amount of amorphous sulfur is distributed uniformly inside MCPs-PAN nanofibers, the thin SEI layer formed during the discharge process can be reverted back after charging and this is critical for ensuring effective sulfur utilization and good cycling stability of the composite. On the other hand, the presence of a large amount of crystalline sulfur active material can lead to the generation of thick and dense SEI layer on the surface of the nanofibers which consequently leads to poor sulfur utilization and capacity retention.

Lithium-selenium (Li-Se) batteries have been considered as alternatives to Li-S batteries with some additional advantages, including higher electrical conductivity, higher energy density, and better cyclability. LiSe batteries exhibit lower theoretical specific capacity $\left(678 \mathrm{~mA} \mathrm{~h} \mathrm{~g}^{-1}\right)$ compared to that of Li-S batteries (1670 $\mathrm{mA} \mathrm{h} \mathrm{g}^{-1}$ ) due to the smaller mass of selenium compared to sulfur. ${ }^{104}$ However, due to the much higher density 


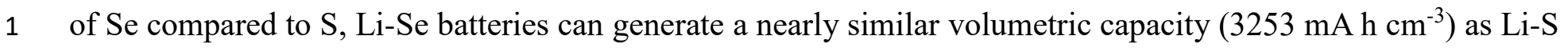
2 batteries $\left(3467 \mathrm{~mA} \mathrm{~h} \mathrm{~cm}^{-3}\right)$, and therefore, similar energy and power densities. Furthermore, the electrical 3 conductivity of selenium $\left(1 \times 10^{-3} \mathrm{~S} \mathrm{~m}^{-1}\right)$ is significantly higher than that of sulfur $\left(5 \times 10^{-28} \mathrm{~S} \mathrm{~m}^{-1}\right)$, thus 4 highlighting another advantage of Li-Se batteries over Li-S batteries. ${ }^{72}$ Similar to Li-S batteries, the Se cathode 5 in Li-Se batteries also undergoes volume expansion upon reaction with lithium due to the incapability of the Se 6 lattice structure to accommodate the insertion of $\mathrm{Li}^{+}$as result of insufficient space. In addition, the Se cathode 7 also suffers from the dissolution issue of high-order lithium selenides $\left(\operatorname{Li}_{2} \operatorname{Se}_{x}, x>4\right)$ in electrolytes, which often 8 leads to low Se utilization, inferior capacity, and poor cycling stability. To mitigate this issue, it is desirable to distribute the electroactive Se materials uniformly in a conductive porous matrix in which there is a sufficient space to accommodate the expansion of the Se cathode. However, at present, it is still challenging to optimize the size of the micropores because very small micropores will lead to poor accommodation of the electroactive material and sluggish $\mathrm{Li}^{+}$diffusion. ${ }^{104}$ In contrast, larger micropores can facilitate improved Se dissolution during cycling and decrease capacity fading, thereby leading to enhanced electrochemical performance. Ideally, the size of the micropores needs to be larger than $1 \mathrm{~nm}$ to enable accommodation of $\mathrm{Se}_{8}$ molecules. Apart from microporous carbon, mesoporous carbon also can also offer a suitable matrix for accommodating the Se electroactive material to enable stable cycling performance.

In order to combine the advantages of micropores and mesopores, activated bimodal porous carbon nanofibers (BP-CNFs) have been prepared by the carbonization of ZIF-8/PAN nanofibers followed by KOH activation for Li-Se batteries. ${ }^{105}$ Fig. 7a depicts the formation of BP-CNFs homogeneously filled with chainlike Se from the combined electrospinning and carbonization of ZIF-8/PAN nanofibers. In the first step, the PAN/ZIF-8 nanofibers were prepared via electrospinning using a solution containing ZIF-8 nanoparticles and PAN. Following heat treatment at $800{ }^{\circ} \mathrm{C}$ under argon atmosphere, mesoporous carbon nanofibers (M-CNFs) (Fig. 7b and 7c) were achieved from the carbonization of organic linkers in ZIF-8 and PAN, and removal of the remaining Zn metal by etching with hydrochloric acid. To activate the M-CNFs, the etched M-CNFs were reacted with $\mathrm{KOH}$ and calcined at $800{ }^{\circ} \mathrm{C}$ in an argon atmosphere. Finally, the Se-loaded BP-CNFs (BP$\mathrm{CNFs} / \mathrm{Se}$ ) were synthesized through a melt-diffusion process by mixing the BP-CNFs with Se powder followed by final heating of the resulting mixture under argon atmosphere. The confinement of chain-like Se within the mesopores of BP-CNFs generated by the $\mathrm{KOH}$ activation and the presence of graphitic carbon are evident in Fig. 7d-h. When evaluated as a cathode host for Li-Se batteries, the BP-CNFs/Se electrode exhibited excellent cycling stability with a high capacity retention of $79.2 \%$ after 300 cycles $\left(588 \mathrm{~mA} \mathrm{~h} \mathrm{~g}^{-1}\right)$ at a current density of $0.5 \mathrm{C}$ (Fig. 7i), along with high rate performance. Specifically, the discharge capacities of the BP-CNFs/Se cathode at current densities of $0.5,1.0,2.0,5.0$, and $10.0 \mathrm{C}$ were 696, 670, 645, 607, and $568 \mathrm{mAh} \mathrm{g}^{-1}$, respectively (Fig. 7j). In comparison, the discharge capacities of M-CNF/Se greatly decreased from 60 to $1 \mathrm{~mA}$ 
$1 \mathrm{~h} \mathrm{~g}^{-1}$ with the increase in current density from 0.5 to $10.0 \mathrm{C}$. The high discharge capacities and excellent rate 2 performance of the BM-CNFs/Se electrode for Li-Se batteries were attributed to the presence of bimodal pores 3 (mesopores and micropores) generated by the carbonization of ZIF-8 nanoparticles and KOH activation, which 4 promoted high utilization of chain-like selenium in the micropores and ensured easy access of electrolyte 5 through the micropores.

\subsection{Fuel cells}

In the past few years, polymer electrolyte membrane fuel cells (HER), a new type of sustainable energy conversion technologies, have gained significant attention due to their excellent efficiency, high energy density and negligible emission of harmful gases. ${ }^{106}$ The performance of PEMFC mainly depends on several important electrocatalytic reactions, such as oxygen reduction reaction (ORR), hydrogen evolution reaction (HER), and oxygen evolution reaction (OER). ${ }^{106-108}$ At present, the major challenge associated with PEMFC is the slow reaction kinetics of ORR at the cathode, in which a large quantity of catalysts is needed to produce sufficient energy output. Currently, Pt-based catalysts are the most commonly used catalysts for ORR. ${ }^{109-113}$ However, Pt catalysts exhibit several disadvantages, such as high cost, poor stability, the crossover effect, and CO poisoning. ${ }^{114}$ These drawbacks have limited the wider commercialization of PEMFCs. As such, it is highly desirable to replace expensive Pt-based catalysts with non-noble metal electrocatalysts which exhibit high catalytic activity, low cost, and excellent long-term cycling stability.

MOF-derived NPCs, especially heteroatom-doped NPCs, with high surface area, high chemical stability, and tunable structure have shown some promise for electrocatalytic reactions. ${ }^{39,41}$ However, due to the inherent presence of micropores in MOFs, MOF-derived NPCs usually have a micropore-dominated structure which hinders electron and mass transport and therefore, lowers the overall reaction kinetics. 1D porous or hollow carbon nanostructures, such as carbon nanotubes (CNTs) and CNFs have attracted considerable interest for ORR owing to their large surface area, high strength to weight ratio, excellent electrical conductivity and good stability, characteristics hich are highly desired for ORR catalysts. ${ }^{80}$ However, pure CNTs or CNFs do not possess sufficiently high catalytic activity toward ORR for fuel cell applications. Therefore, by combining the advantages of MOF-derived NPCs and porous/hollow CNFs, CNFs with hierarchical porosity (mesopores and micropores) and heteroatomic doping, novel catalysts with high electrocatalytic performance for fuel cell reactions can be achieved. In such catalysts, the hierarchical pores are beneficial for enhancing the effective surface area and facilitating mass transportation, while the uniform multiheteroatom doping can enhance the overall conductivity and catalytic performance, such as N-doping which can promote redistribution of atomic charge density and spin density, in nanocarbons, which in turn promotes better oxygen adsorption and reduction. ${ }^{106}$ 
For example, nitrogen-enriched carbon fibers with hierarchical micro-mesoporous structures (NEMCF) were previously synthesized through the in-situ confinement pyrolysis of electrospun ZIF-8/PVP fibers at 900 ${ }^{\circ} \mathrm{C}$, which showed high catalytic activity for ORR ${ }^{84}$ The origin of the mesopores in the fabricated NEMCF was attributed to the strong cohesive interface interaction between PVP-derived carbon and ZIF-8 polyhedrons, which provided a significant confinement effect to maintain the ZIF-8-derived carbon adjacent to the internal surface of PVP-derived carbon during the pyrolysis process, thereby shrinking the ZIF-8-based framework from center to outside, leading to the formation of uniform mesoporous structure. Benefiting for the hierarchical meso-microporous structure and the rich nitrogen doping (6.06 at. \%), the 1D NEMCF showed slightly higher catalytic activity together with enhanced stability and methanol resistance compared to commercial $30 \mathrm{wt} \%$ $\mathrm{Pt} / \mathrm{C}$ catalyst in $0.1 \mathrm{M} \mathrm{KOH}$. Specifically, the hierarchical porous structure allowed for rapid mass transfer and persistent exposure of active sites, avoiding the temporary or permanent deactivation of these sites due to the blocking or collapse of the catalyst pores. In addition, the relatively high proportions of pyridinic and graphitic $\mathrm{N}$ sites on the surface of the NEMCF resulted in high electron conductivity. In general, the graphitic $\mathrm{N}$ determines the limiting current density, whereas the pyridinic $\mathrm{N}$ is likely to improve the onset potential due to the conversion of the reaction route from a $2 e^{-}$-dominated process to a $4 e^{-}$-dominated process. The study further revealed that the types of the active sites and their space distribution are more important in determining the ORR activity and selectivity of the NEMCF than the total nitrogen content.

In order to enhance the electrocatalytic activity of MOF-derived 1D PCNFs or HCNFs for ORR, multiheteroatomic doping (e.g., N, Co, P, B, S, etc.) is often implemented to modify their surface polarity and electronic properties of nanocarbons. For instance, Jia and co-workers reported a simple one-step method for the tunable synthesis of Co-N doped carbon microsphere/nanofiber hybrids (CSFHs) via electrospinning of ZIF-67 and PAN and demonstrated the possible morphology control from a pearl necklace-like nanofiber to a microsphere/nanofibers 3D structure by controlling the ratio of ZIF-67/PAN. ${ }^{115}$ When evaluated for ORR, the CSFHs obtained with ZIF-67/PAN ratio of $8: 1$ and calcined at $800{ }^{\circ} \mathrm{C}$ showed comparable catalytic activity to commercial Pt/C electrode, as indicated by onset potential $\left(E_{\text {onset }}\right)$ of $0.845 \mathrm{~V}$ and half-wave potential $\left(E_{1 / 2}\right)$ of $0.794 \mathrm{~V}$. Furthermore, the CSFH electrode exhibited a Tafel slope of $150 \mathrm{mV}$ per decade, better than the Pt/C electrode (161 mV per decade), inidicating its high kinetic activity for ORR. Meanwhile, the $\mathrm{H}_{2} \mathrm{O}_{2}$ yield and electron transfer number $(n)$ measured using the CSFH electrode were below $3.0 \%$ and $c a .3 .99$ at all potentials in $0.5 \mathrm{M} \mathrm{H}_{2} \mathrm{SO}_{4}$, which are relatively similar to those of the $\mathrm{Pt} / \mathrm{C}$ electrode. The excellent ORR activity of the CSFHs was attributed to the synergistic effects of the high surface area, the large quantity of micropores, and Co-N doping.

$\mathrm{N}$, Co-containing MOF-based hierarchical carbon fibers have previously been synthesized by incorporating bimetallic $\mathrm{Zn}$, Co-ZIF with electrospun $\mathrm{Co}^{2+} / \mathrm{PAN}$ fibers (Fig. 8a and 8b). The resulting $\mathrm{Zn}$, Co-ZIF based 
1 carbon fibers (ZCP-CFs) inherited the merits of carbons from both MOFs and PAN fibers and they exhibited several desirable characteristics for ORR, including large surface areas, high degree of graphitization, highly dispersed $\mathrm{N}$ and $\mathrm{Co}$ active species and excellent electrical conductivity. As a result of these advantageous features, the ZCP-CFs displayed high activity for ORR in $0.1 \mathrm{M} \mathrm{KOH}$, including more positive half-wave potential $(0.135 \mathrm{~V} v s . \mathrm{Ag} / \mathrm{AgCl})$, higher diffusion-limited current density $\left(5.95 \mathrm{~mA} \mathrm{~cm}^{-2}\right)$ and kinetic-limiting currents, lower Tafel slope $\left(62 \mathrm{mV} \mathrm{dec}^{-1}\right)$ higher selectivity (number of electron transferred, $n=3.97$ ) compared to Zn, Co-ZIF derived carbon (ZIF-C). and Zn, Co-ZIF free carbon fiber (CP-CFs) (Fig. 8c and 8d). More notably, the ZCP-CFs catalyst exhibited very close ORR activity to the commercial Pt/C catalyst, but with improved durability and better tolerance to methanol crossover. The above studies clearly indicate that high surface area, high electrical conductivity by Co and N-doping, and hierarchical porosity are essential for enhancing the ORR activity of MOF-derived carbon materials.

In another report, multiheteroatom-doped (N, B, P, and S heteroatom-doped) hierarchical porous carbon nanofibers (denoted as carbon NBPS) synthesized using ZIF-8 coated worm-like micelles have been investigated as catalyst for ORR. ${ }^{116}$ To fabricate such complex multiheteroatom-doped porous CNFs, polymeric worm-like micelles were initially prepared through the self-assembly of poly(ethylene glycol)-block-poly(4vinylpyridine) $\left(\mathrm{PEG}_{113}-b-\mathrm{P}_{4} \mathrm{VP}_{118}\right)$ micelles and DNA followed by cross-linking with 1, 4-dibromobutane. In this case, the polymeric worm-like micelles serve as a source of multiheteroatomic doping and hierarchical porosity, which contributed the excellent textural characteristics of the porous CNFs following carbonization. Subsequently, 3D network of ZIF-8 nanofibers was obtained through the in-situ crystallization of ZIF-8 on the surface of the polymeric worm-like micelles, which exhibited hierarchical porosity, including macropores, mesopores, and micropores. Such network formation was promoted by the likelihood of the coated ZIF-8 particles to fuse and interconnect together to form cross-linking points. The doping of the hierarchical porous CNFs with $\mathrm{B}, \mathrm{P}$, and $\mathrm{S}$ was achieved by dispersing in solutions containing $\mathrm{B}_{4} \mathrm{O}_{7}{ }^{2-}, \mathrm{HPO}^{2-}$, and $\mathrm{SO}_{4}{ }^{2-}$, respectively, and the absorption rate of these ions could be controlled to allow concentration tuning of these dopants. When evaluated as a catalyst for ORR, the carbon NBPS showed an onset potential of $-0.086 \mathrm{~V}$, comparable to that of commercial $20 \% \mathrm{Pt} / \mathrm{C}$ catalyst $(-0.074 \mathrm{~V})$, but with superior methanol tolerance and longterm durability. Specifically, the order of ORR activity was revealed to be: $20 \% \mathrm{Pt} / \mathrm{C}>$ carbon NBPS $>$ carbon $\mathrm{NBP}>$ carbon NBS $=$ carbon NPS $>$ carbon NS $>$ carbon NB $>$ carbon NP $>$ carbon N. The excellent catalytic activity of the carbon NPBS was largely contributed by the existence of multiheteroatomic doping and the the hierarchical pores with abundant micropores, mesopores, and macropores which facilitated the fast mass transportation of reactants and provided extensive contact between reactants and active sites as well as the 1D carbon nanofibrous network which promoted improved electron transfer.

In recent years, research on the development of bifunctional catalysts for water splitting is rapidly 
1 increasing. Molybdenum disulfide $\left(\mathrm{MoS}_{2}\right)$ is an efficient catalyst for HER, yet its low electrical conductivity restricts its charge transfer rate and electrocatalytic performance. To address this issue, $\mathrm{MoS}_{2}$ nanosheets were grown on ZIF-67/PAN-derived carbon fibers $\left(\mathrm{CoNC} @ \mathrm{MoS}_{2}\right)$ to improve their electrical conductivity, as schematically illustrated in Fig. 8e. ${ }^{117}$ In order to obtain CoNC@MoS $\mathrm{M}_{2}$, uniform PAN nanofiber films were initially prepared through electrospinning technique. Next, leaf-like ZIFs (ZIF-L) were directly grown on PAN nanofibers through a simple liquid-phase deposition method at room temperature. Then, the MOF particles on the nanofibers were carbonized at $800{ }^{\circ} \mathrm{C}$ under nitrogen atmosphere to form $\mathrm{Co}, \mathrm{N}$-doped carbon flakes grafted on CNF films (CoNC/CNF). Finally, $\mathrm{MoS}_{2}$ nanostructures were grown on the surface of the leaf-like carbon flakes through a facile solvothermal treatment with ammonium thiomolybdate $\left(\left(\mathrm{NH}_{4}\right)_{2} \mathrm{MoS}_{4}\right)$ at $200{ }^{\circ} \mathrm{C}$, leading to the formation of $\mathrm{CoNC} @ \mathrm{MoS}_{2} / \mathrm{CNF}$ films. The resulting CoNC@ $\mathrm{MoS}_{2} / \mathrm{CNF}$ films exhibited unique hierarchical architectures with interconnected vine-like CNFs, which imparted good flexibility and excellent electrical conductivity for both HER and OER.

For HER measured in $1 \mathrm{M} \mathrm{KOH}$ electrolyte, the CoNC@ $\mathrm{MoS}_{2} / \mathrm{CNFs}$ displayed remarkable HER catalytic activity, in which the overpotential required to generate a current density of $10 \mathrm{~mA} \mathrm{~cm}{ }^{-2}\left(\eta_{10}\right)$ was $143 \mathrm{mV}$, superior than those of $\mathrm{CNF}$, CoNC/CNF, and $\mathrm{MoS}_{2} / \mathrm{CNF}(673 \mathrm{mV}, 425 \mathrm{mV}$ and $257 \mathrm{mV}$, respectively). Furthermore, the CoNC@ $\mathrm{MoS}_{2} / \mathrm{CNF}$ electrode delivered a low Tafel slope of $68 \mathrm{mV}$, which was superior to those of $\mathrm{CoNC} / \mathrm{CNF}\left(79 \mathrm{mV}^{-1}\right)$ and $\mathrm{MoS}_{2} / \mathrm{CNF}\left(89 \mathrm{mV}^{-1}\right)$, indicating its fast HER catalytic kinetics. Furthermore, when employed in OER in $1 \mathrm{M} \mathrm{KOH}$ electrolyte, the CoNC@ $\mathrm{MoS}_{2} / \mathrm{CNFs}_{\text {displayed superior }}$ catalytic activity with a low $\eta_{10}$ value of $350 \mathrm{mV}$, which was superior to those of $\mathrm{MoS}_{2} / \mathrm{CNF}$ and $\mathrm{CoNC} / \mathrm{CNF}$ (570 $\mathrm{mV}$ and $430 \mathrm{mV}$, respectively) (Fig. 8f). In addition, the CoNC@ $\mathrm{MoS}_{2} / \mathrm{CNFs}$ also exhibited a low Tafel slope of $51.9 \mathrm{mV}^{-1}$, which was significantly lower than those of CoNC/CNF $\left(89.7 \mathrm{mV}^{-1}\right), \mathrm{MoS}_{2} / \mathrm{CNF}(119.3$ $\left.\mathrm{mV}^{-1}\right)$, and $\mathrm{RuO}_{2}\left(98.1 \mathrm{mV}^{-1}\right)$ (Fig. 8g), thereby indicating the enhanced catalytic kinetics and high catalytic activity of CoNC@ $\mathrm{MoS}_{2} / \mathrm{CNFs}$. Moreover, an increase of only $17 \mathrm{mV}$ in the value of $\eta_{100}$ was observed after 1500 continuous cycles (Fig. 8h), indicating the excellent OER stability of CoNC@ $\mathrm{MoS}_{2} / \mathrm{CNFs}$ in a basic medium. The enhanced HER and OER activities of the CoNC@ $M o \mathrm{~S}_{2} / \mathrm{CNF}$ were attributed to the presence of hierarchically porous carbon fibers which not only allowed rapid mass transport but also provide a 'highway' for fast electron transfer, thereby confirming the superiority of MOF-derived HCNFs. The above studies clearly highlight the potential of hybrid nanostructures assembled from MOFs and CNFs as efficient self-supported electrocatalysts, thus opening new possibilities into the development of functional free-standing materials for fuel cell applications. 


\section{Conclusions and prospects}

Electrospun MOF-derived 1D hollow carbon nanofibers (HCNFs) have emerged as promising materials for energy storage and conversion applications. HCNFs can overcome the limitations of MOF-derived NPCs, so that long cycle life, high capacity/capacitance and/or high catalytic activity can be realized. In this mini review,

the preparation method, the formation mechanism, and the structure-activity relationship of MOF-derived HCNFs have been summarized. From our survey of the literatures, it is deduced that the composition of the MOFs, the thermal treatment conditions, and post-treatment are critical factors which need to be considered to obtain HCNFs with large surface area, high electrical conductivity and hierarchical porosity, which are beneficial for enhancing their electrochemical performance for EES applications. Despite the rapid progress on MOF-derived HCNFs for EES applications, this research field requires further developments. More efforts should be devoted to realizing the practical applications of HCNFs by focusing on the following points: (a) Many previous works were focused mainly on the synthesis of MOF-derived HCNFs and investigation of their supercapacitive or electrocatalytic performance, thus more theoretical studies are needed to provide more insights into the structure-activity relationship; (b) Previously reported studies were focused mainly on ZIFderived HCNFs, whereas other common MOFs, such as MIL and Prussian blue (PB) series are far less explored, hence future studies should attempt to explore the potential of these MOFs as precursors for the derivation of HCNFs; (c) Future works should address the challenges in assembling MOF-derived HCNFs into flexible or wearable energy storage devices. Overall, the electrospinning method has provided a new and exciting avenue for fabricating functional 1D hollow carbon materials from MOFs, especially for clean energy utilization. It is expected that the electrochemical performance of HCNFs for energy storage and conversion applications may be further improved in the future by doping with several active elements or forming heterostructures with other conductive inorganic or organic nanomaterials. We anticipate that this mini review may provide researchers with some guidance for developing new MOF-based electrochemical devices in the future.

\section{Acknowledgements}

We acknowledge the National Natural Science Foundation of China (NSFC) (51678307) and Postgraduate Research \& Practice Innovation Program of Jiangsu Province (KYCX17_0394) for providing financial support. Y. V. Kaneti thanks the Japan Society for Promotion of Science for providing the standard JSPS Postdoctoral Fellowship. 
$2 \quad$ 1. P. C. Burns, R. C. Ewing and A. Navrotsky, Science, 2012, 335, 1184.

3 2. T. W. Patzek and G. D. Croft, Energy, 2010, 35, 3109-3122.

4 3. A. Banerjee, K. E. Halvorsen, A. Eastmond-Spencer and S. R. Sweitz, Environ. Manage., 2017, 59, $912-923$.

5 4. S. Peng, G. Jin, L. Li, K. Li, M. Srinivasan, S. Ramakrishna and J. Chen, Chem. Soc. Rev., 2016, 45, $1225-1241$.

6 5. S. Zheng, X. Li, B. Yan, Q. Hu, Y. Xu, X. Xiao, H. Xue and H. Pang, Adv. Energy Mater., 2017, 7, 1602733.

$7 \quad 6 . \quad$ R. F. Service, Science, 2006, 313, 902.

$8 \quad 7 . \quad$ G. Wang, L. Zhang and J. Zhang, Chem. Soc. Rev., 2012, 41, 797-828.

9 8. Y. Wang, Y. Song and Y. Xia, Chem. Soc. Rev., 2016, 45, 5925-5950.

J. Nai, Y. Lu, L. Yu, X. Wang and W. Lou Xiong, Adv. Mater., 2017, 29, 1703870.

Y. Guan Bu, L. Yu and W. Lou Xiong, Adv. Sci., 2017, 4, 1700247.

J. Zhang, Z. Zhao, Z. Xia and L. Dai, Nature Nanotech., 2015, 10, 444.

14. K. Kuhar, A. Crovetto, M. Pandey, K. S. Thygesen, B. Seger, P. C. K. Vesborg, O. Hansen, I. Chorkendorff and K. W. Jacobsen, Energy Environ. Sci., 2017, 10, 2579-2593.

15. Y. Rong, Y. Hu, S. Ravishankar, H. Liu, X. Hou, Y. Sheng, A. Mei, Q. Wang, D. Li, M. Xu, J. Bisquert and H. Han, Energy Environ. Sci., 2017, 10, 2383-2391.

17. C. Zhan, T. Wu, J. Lu and K. Amine, Energy Environ. Sci., 2018, 11, 243-257.

18. W. Long, B. Fang, A. Ignaszak, Z. Wu, Y.-J. Wang and D. Wilkinson, Chem. Soc. Rev., 2017, 46, 7176-7190.

19. S. Cavaliere, S. Subianto, I. Savych, D. J. Jones and J. Roziere, Energy Environ. Sci., 2011, 4, 4761-4785.

20. H. B. Wu and X. W. Lou, Sci. Adv., 2017, 3, 9252.

21. O. M. Yaghi and H. Li, J. Am. Chem. Soc., 1995, 117, 10401-10402.

22. O. M. Yaghi, G. Li and H. Li, Nature, 1995, 378, 703.

23. Q.-L. Zhu and Q. Xu, Chem. Soc. Rev., 2014, 43, 5468-5512.

24. N. S. Bobbitt, M. L. Mendonca, A. J. Howarth, T. Islamoglu, J. T. Hupp, O. K. Farha and R. Q. Snurr, Chem. Soc. Rev., 2017, 46, 3357-3385.

25. A. Ö. Yazaydın, R. Q. Snurr, T.-H. Park, K. Koh, J. Liu, M. D. LeVan, A. I. Benin, P. Jakubczak, M. Lanuza, D. B. Galloway, J. J. Low and R. R. Willis, J. Am. Chem. Soc., 2009, 131, 18198-18199.

26. Y. Chen, S. Zhang, S. Cao, S. Li, F. Chen, S. Yuan, C. Xu, J. Zhou, X. Feng, X. Ma and B. Wang, Adv. Mater., 2017, 29, 1606221.

27. S. Qiu, M. Xue and G. Zhu, Chem. Soc. Rev., 2014, 43, 6116-6140.

28. J.-R. Li, R. J. Kuppler and H.-C. Zhou, Chem. Soc. Rev., 2009, 38, 1477-1504.

29. X. Li, Y. Liu, J. Wang, J. Gascon, J. Li and B. Van der Bruggen, Chem. Soc. Rev., 2017, 46, 7124-7144.

30. Y. Chen, X. Huang, S. Zhang, S. Li, S. Cao, X. Pei, J. Zhou, X. Feng and B. Wang, J. Am. Chem. Soc., 2016, 138, 10810-10813. 
31. J. Lee, O. K. Farha, J. Roberts, K. A. Scheidt, S. T. Nguyen and J. T. Hupp, Chem. Soc. Rev, 2009, 38, 14501459.

32. B. Li, H. M. Wen, Y. Cui, W. Zhou, G. Qian and B. Chen, Adv. Mater., 2016, 28, 8819-8860.

33. W. J. Rieter, K. M. Pott, K. M. L. Taylor and W. Lin, J. Am. Chem. Soc., 2008, 130, 11584-11585.

34. K. Lu, C. He and W. Lin, J. Am. Chem. Soc., 2014, 136, 16712-16715.

35. J. Park, Q. Jiang, D. Feng, L. Mao and H.-C. Zhou, J. Am. Chem. Soc., 2016, 138, 3518-3525.

36. K. M. Choi, H. M. Jeong, J. H. Park, Y.-B. Zhang, J. K. Kang and O. M. Yaghi, ACS Nano, 2014, 8, 7451-7457.

37. G. Yilmaz, M. Yam Kah, C. Zhang, J. Fan Hong and W. Ho Ghim, Adv. Mater., 2017, 29, 1606814.

38. J. Zhou and B. Wang, Chem. Soc. Rev., 2017, 46, 6927-6945.

39. S. Fu, C. Zhu, J. Song, D. Du and Y. Lin, Adv. Energy Mater., 2017, 7, 1700363.

40. W. Zhang, X. Jiang, X. Wang, V. Kaneti Yusuf, Y. Chen, J. Liu, J. S. Jiang, Y. Yamauchi and M. Hu, Angew. Chem. Int. Ed., 2017, 56, 8435-8440.

41. W. Xia, A. Mahmood, R. Zou and Q. Xu, Energy Environ. Sci., 2015, 8, 1837-1866.

42. Y. V. Kaneti, J. Zhang, Y.-B. He, Z. Wang, S. Tanaka, M. S. A. Hossain, Z.-Z. Pan, B. Xiang, Q.-H. Yang and Y. Yamauchi, J. Mater. Chem. A, 2017, 5, 15356-15366.

43. B. Liu, H. Shioyama, T. Akita and Q. Xu, J. Am. Chem. Soc., 2008, 130, 5390-5391.

44. M. Hu, J. Reboul, S. Furukawa, N. L. Torad, Q. Ji, P. Srinivasu, K. Ariga, S. Kitagawa and Y. Yamauchi, J. Am. Chem. Soc., 2012, 134, 2864-2867.

45. K. Shen, X. Chen, J. Chen and Y. Li, ACS Catal., 2016, 6, 5887-5903.

46. X. Cao, C. Tan, M. Sindoro and H. Zhang, Chem. Soc. Rev., 2017, 46, 2660-2677.

47. R. R. Salunkhe, Y. V. Kaneti, J. Kim, J. H. Kim and Y. Yamauchi, Acc. Chem. Res., 2016, 49, 2796-2806.

48. $\quad$ S. Dang, Q.-L. Zhu and Q. Xu, Nat. Rev. Mater., 2017, 3, 17075.

49. R. R. Salunkhe, Y. V. Kaneti and Y. Yamauchi, ACS Nano, 2017, 11, 5293-5308.

50. Y. Z. Chen, C. Wang, Z. Y. Wu, Y. Xiong, Q. Xu, S. H. Yu and H. L. Jiang, Adv. Mater, 2015, 27, 5010-5016.

51. L. Shang, H. Yu, X. Huang, T. Bian, R. Shi, Y. Zhao, I. N. Waterhouse Geoffrey, L. Z. Wu, C. H. Tung and T. Zhang, Adv. Mater., 2015, 28, 1668-1674.

52. J. Tang, R. R. Salunkhe, J. Liu, N. L. Torad, M. Imura, S. Furukawa and Y. Yamauchi, J. Am. Chem. Soc., 2015, 137, 1572-1580.

53. J. Yang, F. Zhang, H. Lu, X. Hong, H. Jiang, Y. Wu and Y. Li, Angew. Chem. Int. Ed., 2015, 54, 10889-10893.

54. Z. Wang, Y. Lu, Y. Yan, T. Y. P. Larissa, X. Zhang, D. Wuu, H. Zhang, Y. Yang and X. Wang, Nano Energy, 2016, 30, 368-378.

55. W. Zhang, X. Jiang, Y. Zhao, A. Carne-Sanchez, V. Malgras, J. Kim, J. H. Kim, S. Wang, J. Liu, J.-S. Jiang, Y. Yamauchi and M. Hu, Chem. Sci., 2017, 8, 3538-3546.

56. C. Liu, X. Huang, J. Wang, H. Song, Y. Yang, Y. Liu, J. Li, L. Wang and C. Yu, Adv. Funct. Mater, 2017, 28, 1705253.

57. Y. Chuan Tan and H. Chun Zeng, Chem. Commun., 2016, 52, 11591-11594.

58. J. Tang and Y. Yamauchi, Nat. Chem., 2016, 8, 638. 
1 59. P. Pachfule, D. Shinde, M. Majumder and Q. Xu, Nat. Chem., 2016, 8, 718.

60. H. Ahn Sung, J. Klein Michael and A. Manthiram, Adv. Energy Mater., 2017, 7, 1601979.

61. G. Xu, B. Ding, L. Shen, P. Nie, J. Han and X. Zhang, J. Mater. Chem. A, 2013, 1, 4490-4496.

62. X.-Y. Yu, Y. Feng, B. Guan, X. W. Lou and U. Paik, Energy Environ. Sci., 2016, 9, 1246-1250.

63. F. Cao, M. Zhao, Y. Yu, B. Chen, Y. Huang, J. Yang, X. Cao, Q. Lu, X. Zhang, Z. Zhang, C. Tan and H. Zhang, J. Am. Chem. Soc., 2016, 138, 6924-6927.

64. T. Y. Ma, S. Dai, M. Jaroniec and S. Z. Qiao, J. Am. Chem. Soc., 2014, 136, 13925-13931.

65. X. F. Lu, L. F. Gu, J. W. Wang, J. X. Wu, P. Q. Liao and G. R. Li, Adv. Mater., 2016, 29, 1604437.

66. G. Zhang, S. Hou, H. Zhang, W. Zeng, F. Yan, C. Li Cheng and H. Duan, Adv. Mater., 2015, 27, $2400-2405$.

67. Q. Wei, F. Xiong, S. Tan, L. Huang, H. Lan Esther, B. Dunn and L. Mai, Adv. Mater., 2017, 29, 1602300.

68. D. Li, C. Lv, L. Liu, Y. Xia, X. She, S. Guo and D. Yang, ACS Central Sci., 2015, 1, 261-269.

69. C. Niu, J. Meng, X. Wang, C. Han, M. Yan, K. Zhao, X. Xu, W. Ren, Y. Zhao, L. Xu, Q. Zhang, D. Zhao and L. Mai, Nat. Commun., 2015, 6, 7402.

70. Z. Li, J. Zhang and W. Lou Xiong, Angew. Chem. Int. Ed., 2015, 54, 12886-12890.

71. Y. Zhao, W. Wu, J. Li, Z. Xu and L. Guan, Adv. Mater., 2014, 26, 5113-5118.

72. J. Zhou, J. Yang, Z. Xu, T. Zhang, Z. Chen and J. Wang, J. Mater. Chem. A, 2017, 5, 9350-9357.

73. Z. Liu, R. Guo, J. Meng, X. Liu, X. Wang, Q. Li and L. Mai, Chem. Commun., 2017, 53, 8284-8287.

74. C.-L. Zhang and S.-H. Yu, Chem. Soc. Rev., 2014, 43, 4423-4448.

75. C.-L. Zhang and S.-H. Yu, Mater. Horiz., 2016, 3, 266-269.

76. X. Lu, C. Wang, F. Favier and N. Pinna, Adv. Energy Mater., 2016, 7, 1601301.

77. Q. Liu, J. Zhu, L. Zhang and Y. Qiu, Renew. Sustain. Energy Rev., 2018, 81, 1825-1858.

78. P. S. Kumar, J. Sundaramurthy, S. Sundarrajan, V. J. Babu, G. Singh, S. I. Allakhverdiev and S. Ramakrishna, Energy Environ. Sci., 2014, 7, 3192-3222.

79. C. Wang, C. Liu, J. Li, X. Sun, J. Shen, W. Han and L. Wang, Chem. Commun., 2017, 53, 1751-1754.

80. C. Liu, J. Wang, J. Li, J. Liu, C. Wang, X. Sun, J. Shen, W. Han and L. Wang, J. Mater. Chem. A, 2017, 5, 12111220.

81. Y. Zhang, S. Yuan, X. Feng, H. Li, J. Zhou and B. Wang, J. Am. Chem. Soc, 2016, 138, 5785-5788.

82. M. Rose, B. Böhringer, M. Jolly, R. Fischer and S. Kaskel, Adv. Eng. Mater., 2010, 13, 356-360.

83. C. Wang, H. Wang, R. Luo, C. Liu, J. Li, X. Sun, J. Shen, W. Han and L. Wang, Chem. Eng. J., 2017, 330, 262271.

84. Q. Lai, Y. Zhao, Y. Liang, J. He and J. Chen, Adv. Funct. Mater., 2016, 26, 8334-8344.

85. G. Lee, Y. D. Seo and J. Jang, Chem. Commun., 2017, 53, 11441-11444.

86. H. Wang, J. Deng, C. Xu, Y. Chen, F. Xu, J. Wang and Y. Wang, Energy Storage Mater., 2017, 7, $216-221$.

87. W. Chaikittisilp, M. Hu, H. Wang, H.-S. Huang, T. Fujita, K. C. W. Wu, L.-C. Chen, Y. Yamauchi and K. Ariga, Chem. Commun., 2012, 48, 7259-7261.

88. L. Wang, Y. Han, X. Feng, J. Zhou, P. Qi and B. Wang, Coord. Chem. Rev., 2016, 307, 361-381.

89. R. R. Salunkhe, C. Young, J. Tang, T. Takei, Y. Ide, N. Kobayashi and Y. Yamauchi, Chem. Commun., 2016, 52, 
4764-4767.

90. C. Tran, R. Singhal, D. Lawrence and V. Kalra, J. Power Sources, 2015, 293, 373-379.

91. S. Guo, H. Shen, Z. Tie, S. Zhu, P. Shi, J. Fan, Q. Xu and Y. Min, J. Power Sources, $2017,359,285-294$.

92. H. Wang, C. Xu, Y. Chen and Y. Wang, Energy Storage Mater., 2017, 8, 127-133.

93. J. Wang, X. Li, Y. Zi, S. Wang, Z. Li, L. Zheng, F. Yi, S. Li and L. Wang Zhong, Adv. Mater., 2015, 27, 48304836.

94. Y.-Z. Zhang, Z.-Z. Wu, G.-L. Pan, S. Liu and X.-P. Gao, ACS Appl. Mater. Interfaces, 2017, 9, 12436-12444.

95. M. Armand and J. M. Tarascon, Nature, 2008, 451, 652.

96. H. Jiang, D. Ren, H. Wang, Y. Hu, S. Guo, H. Yuan, P. Hu, L. Zhang and C. Li, Adv. Mater., 2015, 27, $3687-3695$.

97. Y. Guan Bu, A. Kushima, L. Yu, S. Li, J. Li and W. Lou Xiong, Adv. Mater., 2017, 29, 1605902.

98. M. Chen Yu, L. Yu and W. Lou Xiong, Angew. Chem. Int. Ed., 2016, 55, 5990-5993.

99. Y. Chen, X. Li, K. Park, W. Lu, C. Wang, W. Xue, F. Yang, J. Zhou, L. Suo, T. Lin, H. Huang, J. Li and J. B. Goodenough, Chem, 3, 152-163.

100. A. Eftekhari and D.-W. Kim, J. Mater. Chem. A, 2017, 5, 17734-17776.

101. Y. X. Yin, S. Xin, Y. G. Guo and L. J. Wan, Angew. Chem. Int. Ed., 2013, 52, 13186-13200.

102. R. Elazari, G. Salitra, A. Garsuch, A. Panchenko and D. Aurbach, Adv. Mater, 2011, 23, 5641-5644.

103. B. Zhang, X. Qin, G. R. Li and X. P. Gao, Energy Environ. Sci., 2010, 3, 1531-1537.

104. A. Eftekhari, Sustain. Energy Fuels, 2017, 1, 14-29.

105. S.-K. Park, J.-S. Park and Y. C. Kang, J. Mater. Chem. A, 2018, 6, 1028-1036.

106. Z. Song, W. Liu, N. Cheng, M. Norouzi Banis, X. Li, Q. Sun, B. Xiao, Y. Liu, A. Lushington, R. Li, L. Liu and X. Sun, Mater. Horiz., 2017, 4, 900-907.

107. L. Yang, X. Zeng, W. Wang and D. Cao, Adv. Funct. Mater, 2017, 28, 1704537.

108. B. Y. Guan, L. Yu and X. W. Lou, Energy Environ. Sci., 2016, 9, 3092-3096.

109. N. Cheng, M. Norouzi Banis, J. Liu, A. Riese, S. Mu, R. Li, T.-K. Sham and X. Sun, Energy Environ. Sci., 2015, 8, $1450-1455$.

110. N. Cheng, N. Banis Mohammad, J. Liu, A. Riese, X. Li, R. Li, S. Ye, S. Knights and X. Sun, Adv. Mater., 2014, 27, 277-281.

111. B. Lim, M. Jiang, P. H. C. Camargo, E. C. Cho, J. Tao, X. Lu, Y. Zhu and Y. Xia, Science, $2009,324,1302$.

112. V. Mazumder, M. Chi, K. L. More and S. Sun, J. Am. Chem. Soc., 2010, 132, 7848-7849.

113. L. Yang, M. B. Vukmirovic, D. Su, K. Sasaki, J. A. Herron, M. Mavrikakis, S. Liao and R. R. Adzic, J. Phys. Chem. C, 2013, 117, 1748-1753.

114. M. K. Debe, Nature, 2012, 486, 43.

115. W. Yang, X. Liu, L. Chen, L. Liang and J. Jia, Chem. Commun., 2017, 53, 4034-4037.

116. P. Huang, H. Li, X. Huang and D. Chen, ACS Appl. Mater. Interfaces, 2017, 9, 21083-21088.

117. D. Ji, S. Peng, L. Fan, L. Li, X. Qin and S. Ramakrishna, J. Mater. Chem. A, 2017, 5, $23898-23908$. 


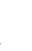




\section{LIST OF FIGURES}

2

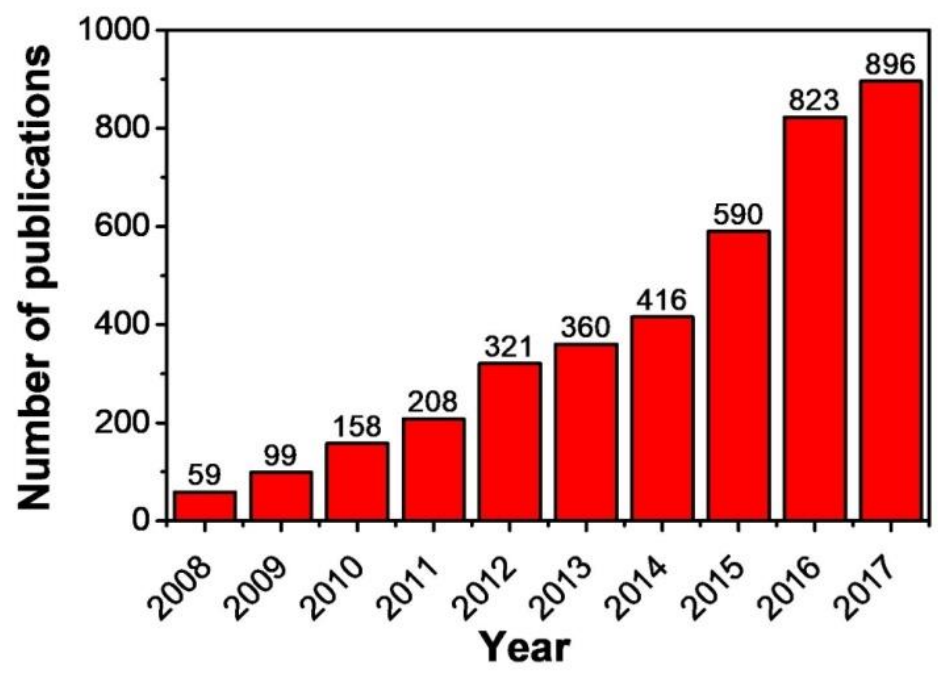

3

Fig. 1. Number of articles published on MOF-derived carbon materials over the last 10 years according to SciFinder 5 Scholar.

6 


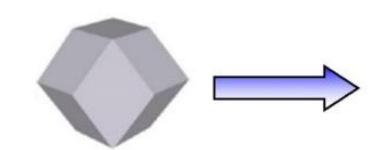

Single metal MOF
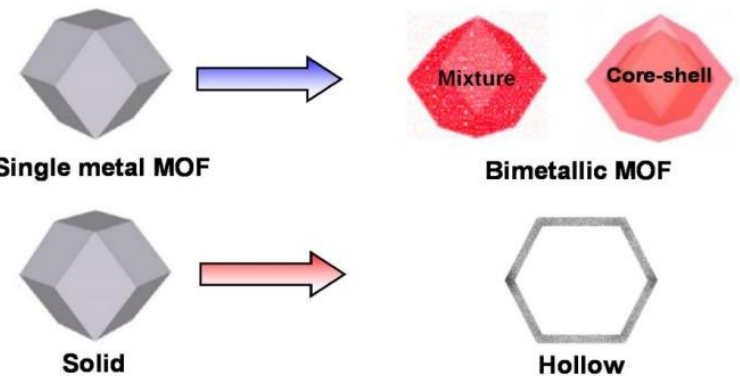

Bimetallic MOF
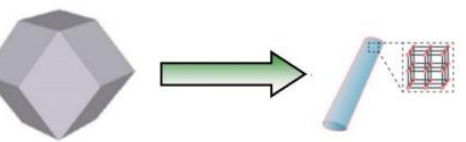

OD polyhedra

1D rods
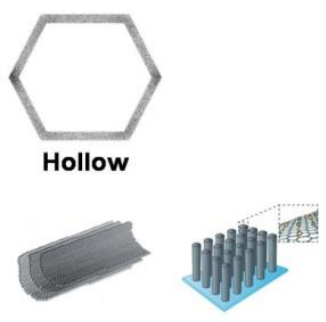

2D sheets 3D arrays

2 Fig. 2. Schematic diagram showing the development of MOF-derived nanomaterials with various dimensionalities and 3 structures. 


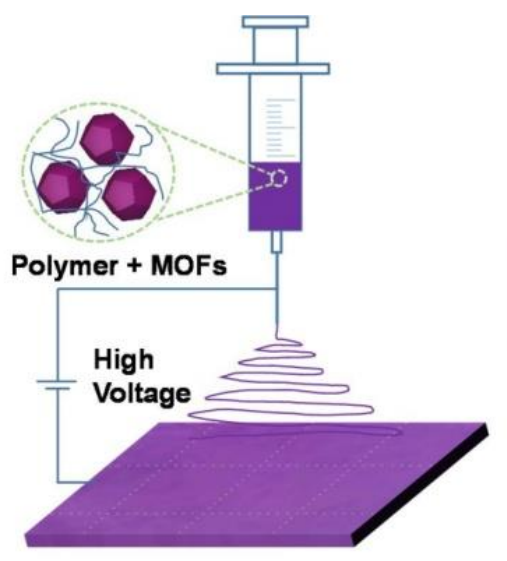

ROUTE I

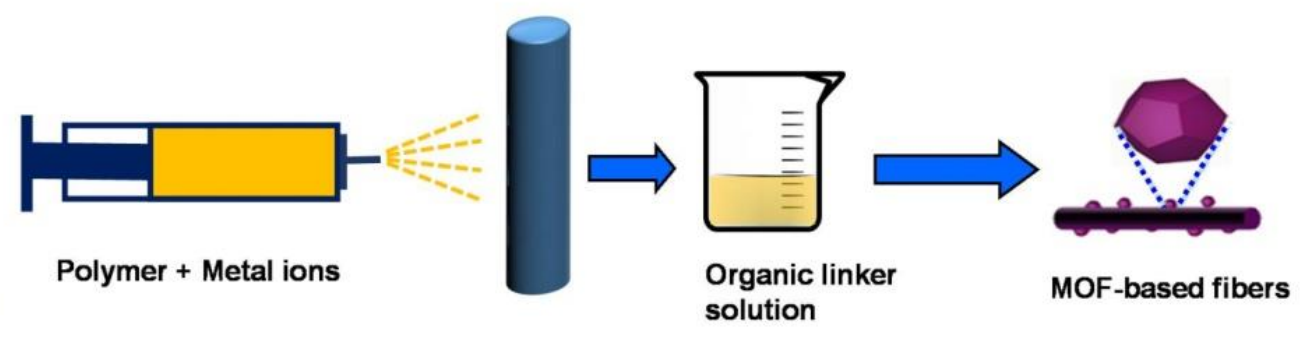

ROUTE II
1

2 Fig. 3. Schematic illustration of the preparation of MOF-based nanofibers by electrospinning: Route I - mixing pre3 fabricated MOF nanoparticles with polymer followed by electrospinning; Route II - electrospun polymer nanofibers $4 \quad$ (containing metal ions) followed by in-situ growth of MOF particles. 


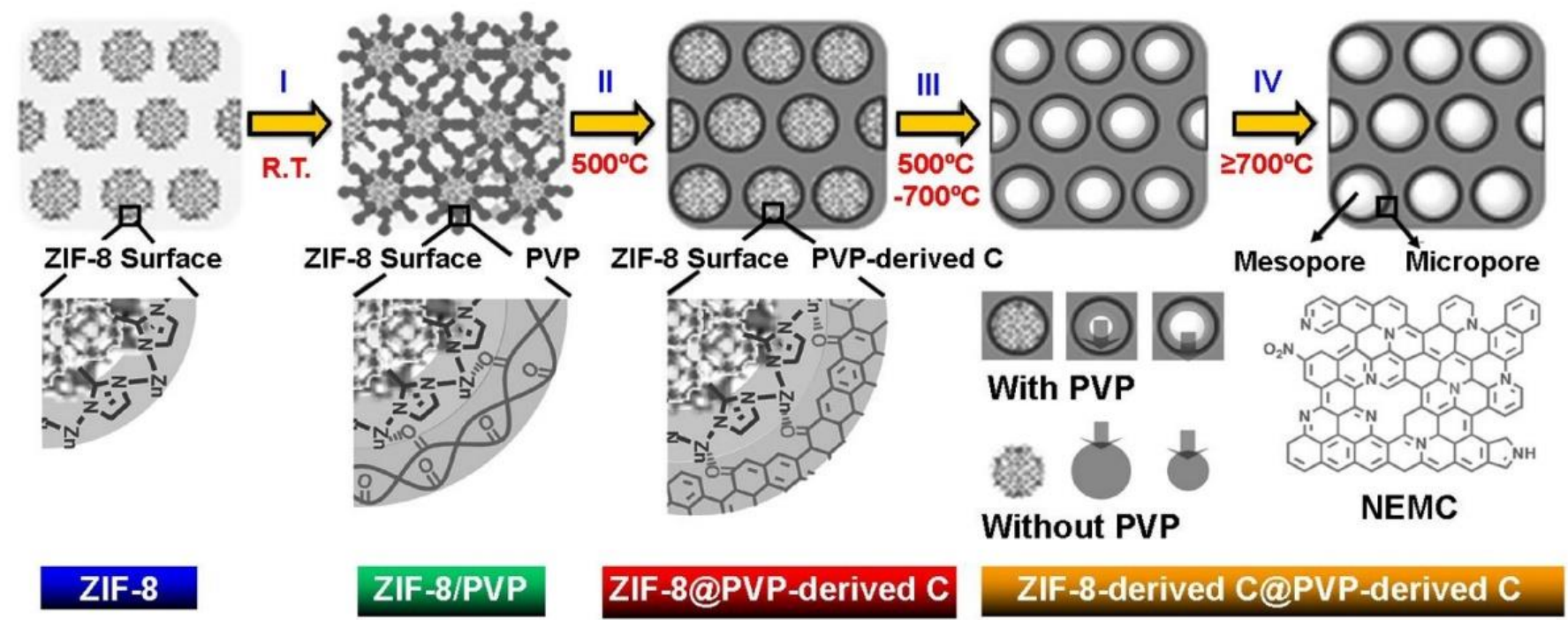

2 Fig. 4. Formation mechanism of hollow carbon nanofibers (HCNFs) from zeolitic imidazolate framework-8 (ZIF3 8)/polyacrylonitrile (PAN) nanofibers. ${ }^{84}$ Copyright 2016, Wiley-VCH. 


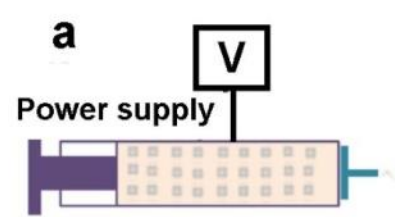

ZIF-8 NPS/PAN/DMF

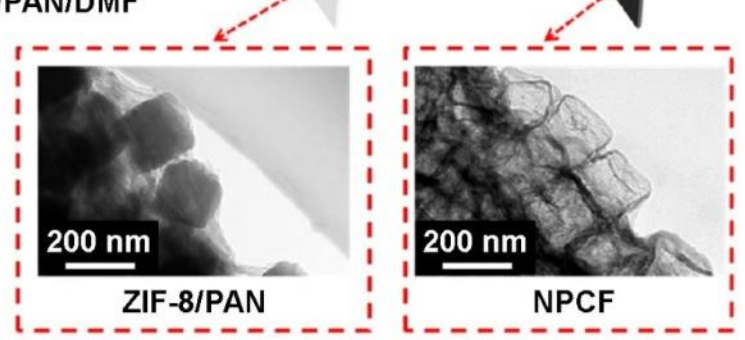

5

1 5 Chemistry.

6
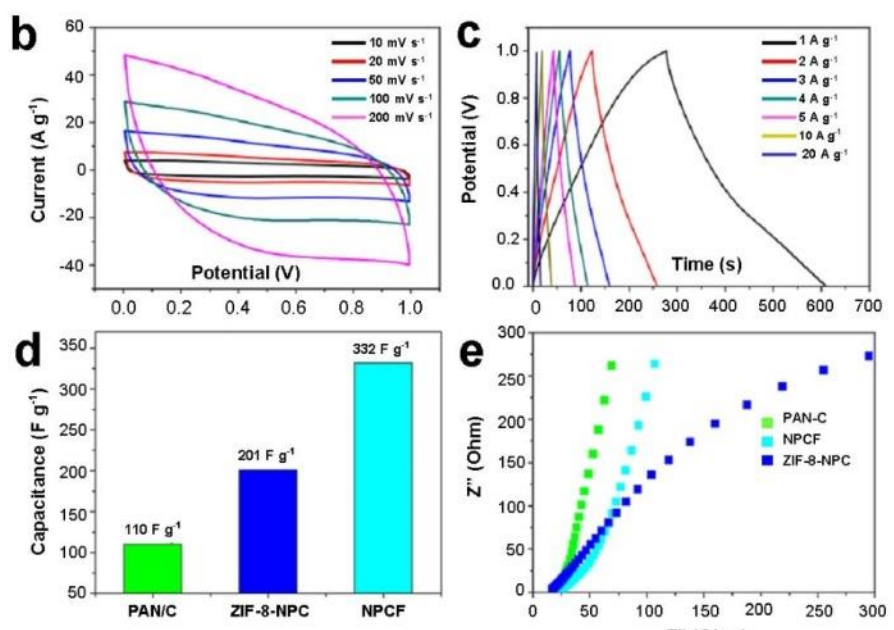

2 Fig. 5. (a) Preparation process of nanoporous carbon fibers (NPCFs). (b) CV curves and (d) galvanostatic charge3 discharge curves of NPCFs. (e) Capacitance and (f) Nyquist electrochemical impedance spectra of PAN-derived carbon 4 (PAN-C), ZIF-8 derived nanoporous carbon (ZIF-8-NPC), and NPCFs. ${ }^{79}$ Copyright 2017, The Royal Society of 

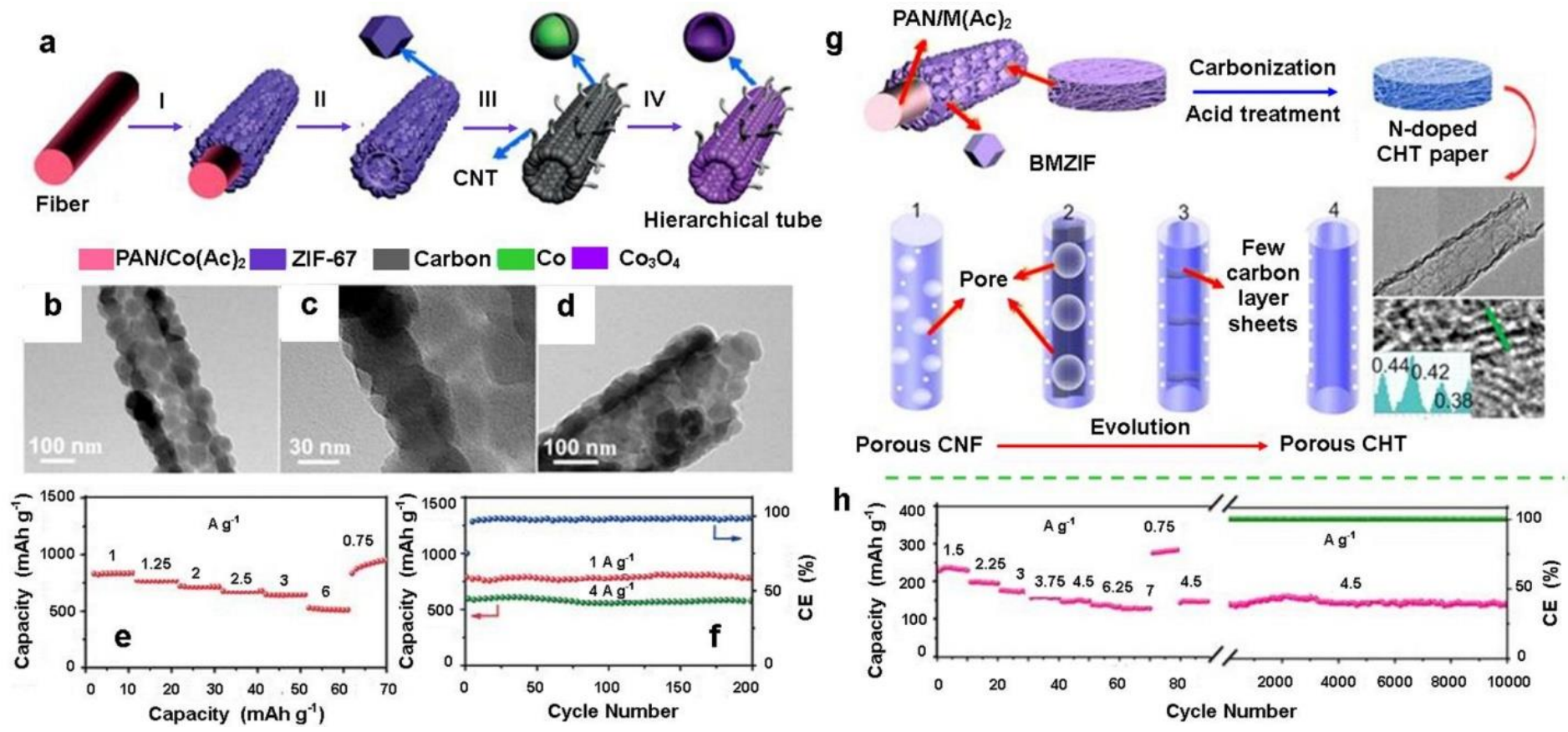

2 Fig. 6. (a) Schematic illustration of the formation of ZIF-67/PAN-derived hierarchical CNT/Co $\mathrm{O}_{4}$ microtubes. (b-d) TEM 3 images of the synthesized ZIF-67 microtubes. Electrochemical properties of the hierarchical $\mathrm{CNT} / \mathrm{Co}_{3} \mathrm{O}_{4}$ microtubes for 4 lithium-ion batteries (LIBs): (e) rate performance and (f) cycling performance and Coulombic efficiency. ${ }^{98}$ Copyright 5 2016, Wiley-VCH. (g) Schematic illustration of the synthesis of a series of 1D nanocarbons from porous N-doped carbon 6 fiber networks (CFNs) to carbon hollow tubes (CHTs) with enlarged graphene interlayer spacing. (h) Rate performance 7 and cycling stability of the porous N-doped carbon hollow tubular structures (CHTS) for LIBs. ${ }^{99}$ Copyright 2017 , Cell 8 Press. 


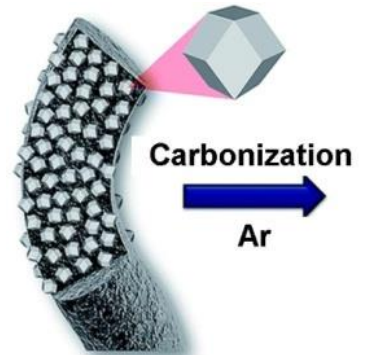

ZIF-8/PAN NF

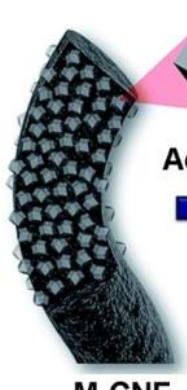

M-CNF

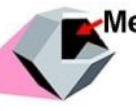

Activation

\section{$\mathrm{KOH}$}
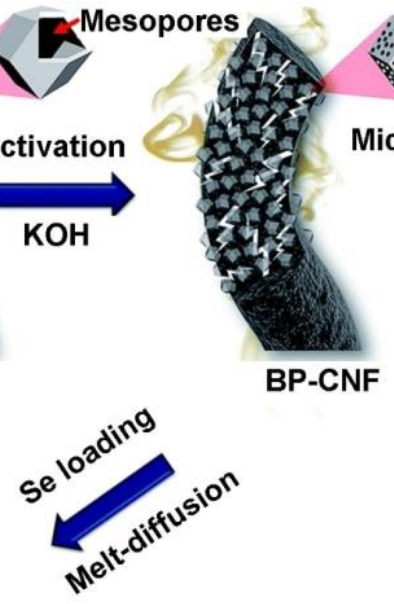

BP-CNF

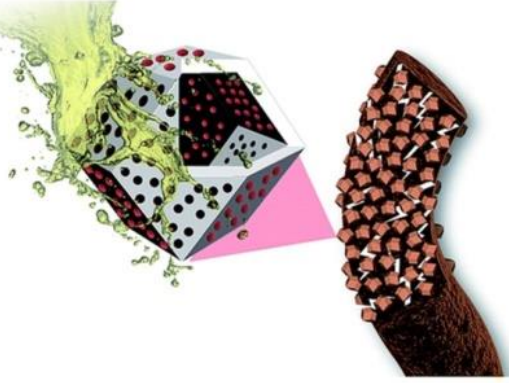

BP-CNF/Se

(i)

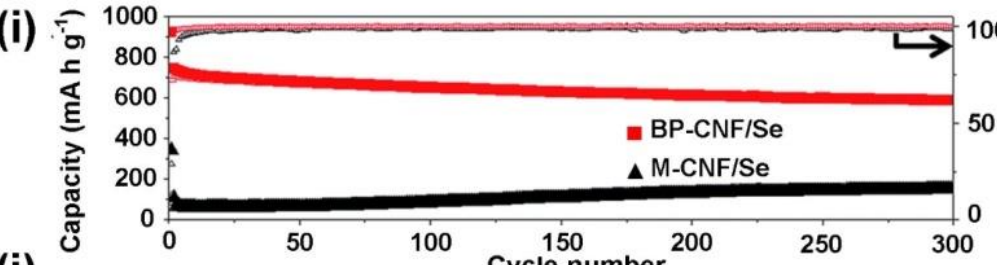

(j)

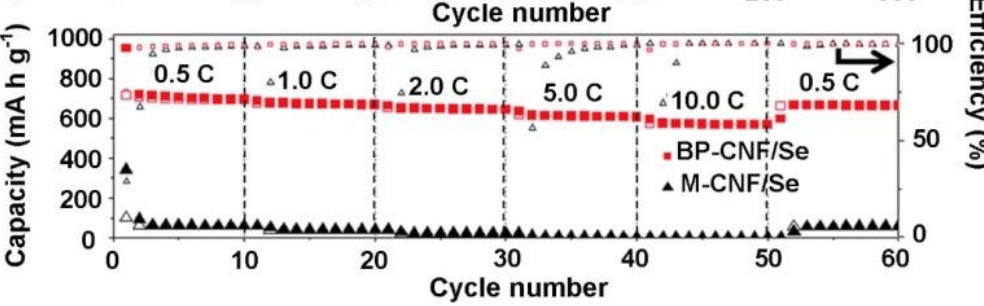

(a)

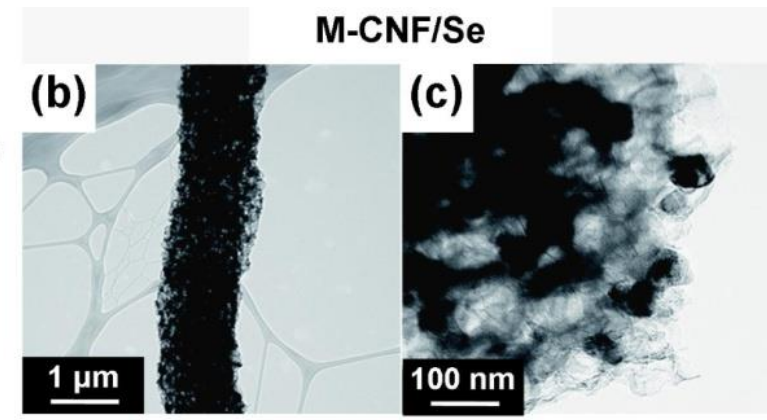

BP-CNF/Se

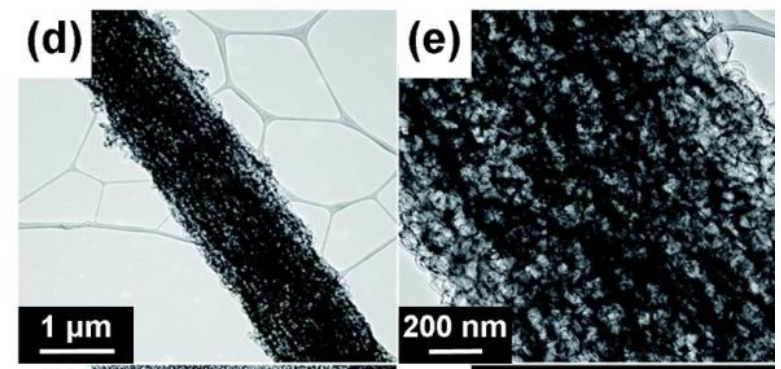

(f)

(g)

Graphitic C

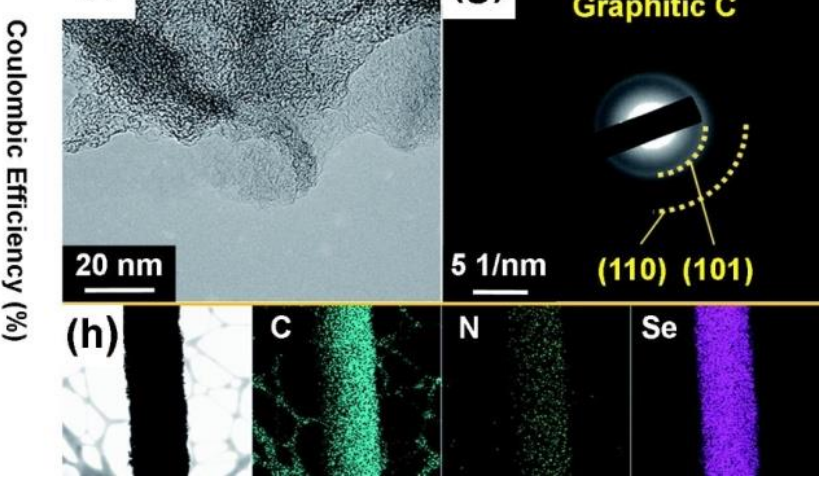

2 Fig. 7. (a) Formation mechanism of bimodal porous nitrogen-doped carbon nanofiber (BP-CNF) homogeneously filled 3 with chain-like Se. (b, c) TEM images of the mesoporous carbon nanofibers (M-CNF). (d, e) TEM images, (f) HRTEM 4 image, (g) SAED pattern, and (h) elemental mapping images of Se-loaded BP-CNF (BP-CNF/Se). Electrochemical 5 properties of $\mathrm{BP}-\mathrm{CNF} / \mathrm{Se}$ and Se-loaded $\mathrm{M}-\mathrm{CNF}(\mathrm{M}-\mathrm{CNF} / \mathrm{Se}$ ) for lithium-selenium (Li-Se) batteries: (i) cycling 6 performance at a current density of $0.5 \mathrm{C}$ and (j) rate performances with the Coulombic efficiencies ${ }^{105}$ Copyright 2017 , 7 The Royal Society of Chemistry. 

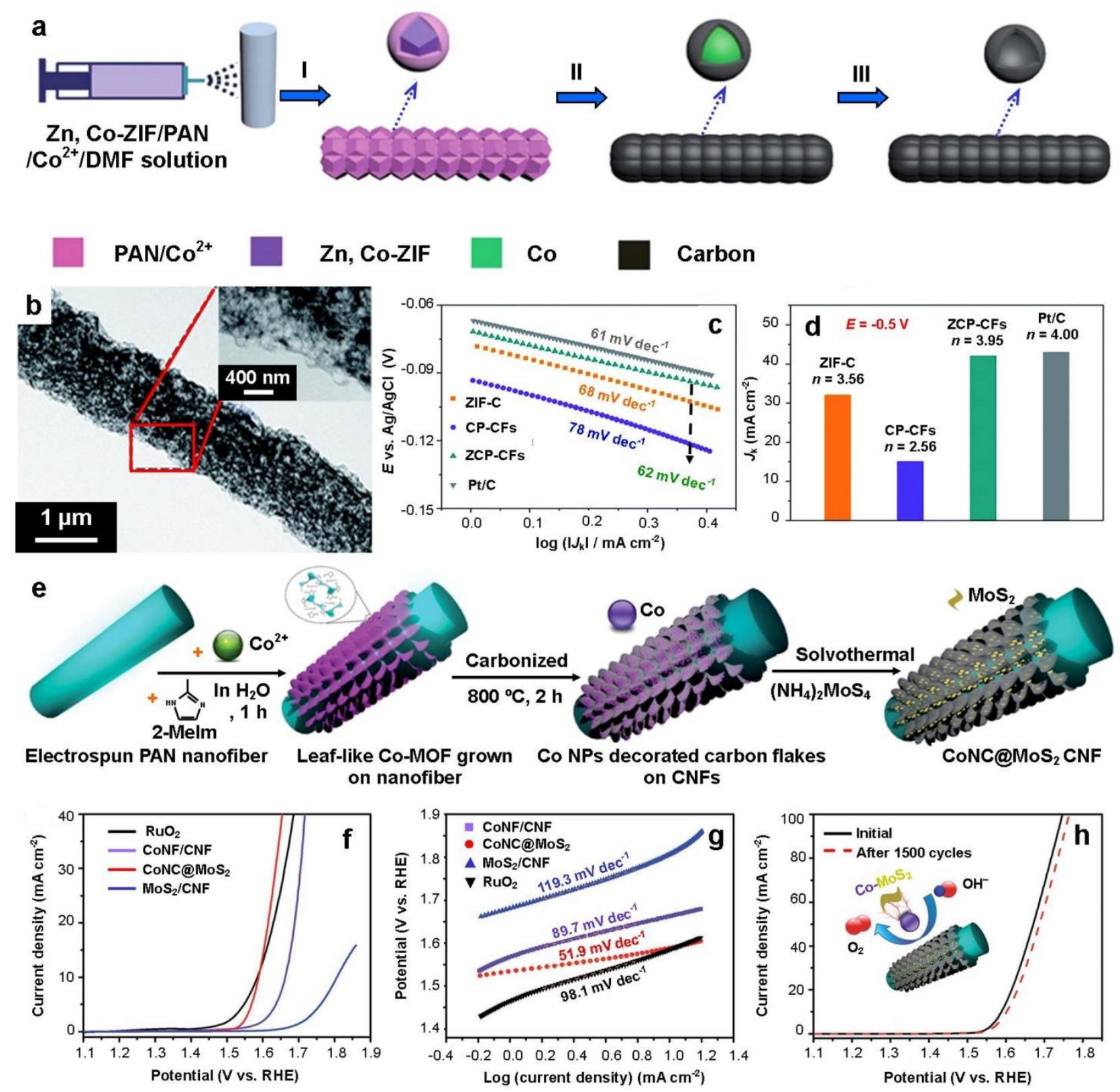

Fig. 8. (a) Schematic illustration of the preparation of the Zn, Co-ZIF-based hierarchical carbon fibers (ZCP-CFs) and (b) the corresponding TEM image of ZCP-CFs. (c) Tafel plots of ZIF-C, CP-CFs, ZCP-CFs and Pt/C. (d) Kinetic-limiting current density of ZIF-C, CP-CFs, ZCP-CFs-9 and Pt/C. ${ }^{80}$ Copyright 2017, The Royal Society of Chemistry. (e) Schematic illustration of the fabrication of free-standing $\mathrm{MoS}_{2}$ nanosheets grafted Co-N-doped carbon flakes grown on electrospun carbon nanofibers (CoNC@ $\mathrm{MoS}_{2} / \mathrm{CNF}$ ). (f) Polarization curves of $\mathrm{CoNC} @ \mathrm{MoS}_{2} / \mathrm{CNF}, \mathrm{MoS} / \mathrm{CNF}$, $\mathrm{CoNC} / \mathrm{CNF}$, and $\mathrm{RuO}_{2}$ in $1 \mathrm{M} \mathrm{KOH}$ in the OER. (g) OER Tafel plots of CoNC@MoS $/ \mathrm{MNF}_{2} \mathrm{MoS}_{2} / \mathrm{CNF}, \mathrm{CoNC} / \mathrm{CNF}$, and $\mathrm{RuO}_{2}$ in $1 \mathrm{M} \mathrm{KOH}$. (h) OER cycling stability of CoNC@MoS $/$ CNFs in 1 M KOH. ${ }^{117}$ Copyright 2017, The Royal Society of Chemistry. 


\section{TABLE OF CONTENT DESCRIPTION}

2 This review summarizes the advances in the derivation of one-dimensional porous and hollow carbon nanofibers from

3 metal-organic frameworks for energy storage and conversion. 